\title{
Manfaat Pijat Refleksi Untuk Mengurangi Depresi Pada Lansia
}

\author{
Dr. R Djadjang A. S.H, M.Kes, Dwi Ratna Sari Handayani Dr., M.K.K., A Imam Waluyo \\ Universitas Binawan \\ rdjadjanga@gmail.com
}

\begin{abstract}
Abstrak
Pertumbuhan pada populasi lansia telah menyebabkan peningkatan penyakit terkait dengan usia, terutama depresi yang mempengaruhi kualitas hidup. Seiring bertambahnya usia pada lansia, depresi juga akan meningkat. Depresi adalah gangguan mental yang umum, ditandai oleh kesedihan, kehilangan minat atau kesenangan, perasaan bersalah atau rendah diri, gangguan tidur atau nafsu makan, perasaan lelah dan konsentrasi yang buruk. WHO memperkirakan bahwa tingkat prevalensi keseluruhan gangguan depresi di kalangan lansia umumnya bervariasi antara 10 dan 20\%, tergantung pada budaya (WHO,2011. Pijat refleksi adalah metode medis komplementer dan alternatif dan merupakan aplikasi manipulasi berbasis tubuh yang sering digunakan (Wang, 2008). Pijat refleksi adalah metode terapi yang bertujuan untuk merangsang organ target dengan pesan elektrokimia yang disampaikan ke organ melalui neuron yang distimulasi melalui titik refleks di tangan dan kaki (Ernst, Lee, 2010). Penelitian yang dilakukan oleh Aydin, Aslan, Yalcin, 2016, pada wanita dengan OAB (Overactive Bladder Symptom) yang memiliki gejala depresi, ditemukan bahwa gejala depresi ringan dan tingkat sedang ditemukan menurun secara berarti setelah dilakukannya pijat refleksi, dan gejala depresi berat ditemukan tidak ada setelah dilakukannya pijat refleksi. Penelitian ini bertujuan untuk mengetahui efektifitas pijat refleksi pada kaki terhadap depresi pada lansia di Desa Puraseda, Kecamatan Leuwiliang, Kabupaten Bogor, Jawa Barat. Penelitian ini menggunakan design quasi experimental design dengan rancangan pre dan post pada kelompok lansia $\geq 60$ tahun. Pada penelitian ini lansia dilakukan wawancara dan observasi dengan GDS terlebih dahulu sebelum mendapat perlakuan. Langkah berikutnya adalah diberikan perlakuan pijat refleksi pada kaki. Setelah selesai intervensi kemudian dilakukan wawancara dan observasi dengan GDS yang kedua. Hasil rata-rata selisih GDS sebelum dan sesudah intervensi dibandingkan untuk melihat sejauh mana pengaruh pijat refleksi pada kaki terhadap depresi setelah dilakukannya pijat refleksi pada kaki.
\end{abstract}

Kata Kunci : Refleksi, Depresi, Lansia

Abstract 
The growth in the elderly population has led to an increase in age-related diseases, especially depression that affects quality of life. As the elderly get older, depression will also increase. Depression is a common mental disorder, characterized by sadness, loss of interest or pleasure, feelings of guilt or low self-esteem, disturbed sleep or appetite, feelings of tiredness and poor concentration. WHO estimates that the overall prevalence rate of depressive disorders among the elderly generally varies between 10 and 20\%, depending on culture (WHO, 2011. Reflexology is a complementary and alternative medical method and is a frequently used application of bodybased manipulation (Wang, 2008). Reflexology is a therapeutic method that aims to stimulate target organs with electrochemical messages that are conveyed to organs through stimulated neurons through reflex points in the hands and feet (Ernst, Lee, 2010). Research conducted by Aydin, Aslan, Yalcin, 2016, in women with OAB (Overactive Bladder Symptom) who have symptoms of depression, it was found that the symptoms of mild and moderate depression were found to decrease significantly after reflexology, and symptoms of major depression were found to be absent after reflexology. This study aims to determine the effectiveness of reflexology. on the legs against depression in the elderly in D esa Puraseda, Leuwiliang District, Bogor Regency, West Java. This study used a quasi-experimental design with pre and post designs in the elderly group 60 years. In this study, the elderly were interviewed and observed with GDS before receiving treatment. The next step is to be given reflexology treatment on the feet. After completing the intervention, interviews and observations were carried out with the second GDS. The results of the average difference in GDS before and after the intervention were compared to see how far the effect of foot reflexology on depression after foot reflexology was done.

Keywords: Reflection, Depression, Elderly

\section{Pendahuluan}

Secara universal, proporsi orang yang berusia di atas 60 tahun tumbuh lebih cepat dari kelompok usia lainnya, PBB setuju batas ambang adalah lebih dari 60 tahun untuk merujuk pada populasi lansia. ${ }^{1}$

Lansia merupakan bagian populasi yang paling cepat berkembang dan depresi adalah salah satu gangguan kejiwaan yang paling umum pada lansia, dan biaya untuk mengobati lansia yang depresi pada masa mendatang akan signifikan, begitu juga dengan biaya perawatan dan pelayananan kesehatan (Bjørkløf et al, 2013). ${ }^{2}$ Menurut World Health Organization (WHO), 2013, ${ }^{3}$ depresi adalah gangguan mental yang umum, ditandai oleh kesedihan, kehilangan minat atau kesenangan, perasaan bersalah atau rendah diri, gangguan tidur atau nafsu makan, perasaan lelah dan konsentrasi yang buruk. Depresi pada orang tua terkait dengan peningkatan angka kematian (Nilson, Gustafson,Hultberg, 2011). ${ }^{4}$

Dalam beberapa tahun terakhir, telah terjadi peningkatan penggunaan aplikasi pengobatan komplementer dan alternatif selain pengobatan modern dalam perlindungan dan perbaikan kesehatan. Pijat refleksi adalah salah satu metode dan merupakan teknik noninvasive yang banyak digunakan (Aydin, Aslan, Yalcin, 2016). ${ }^{5}$ Pijat refleksi adalah metode terapi yang bertujuan untuk merangsang organ target dengan pesan elektrokimia yang disampaikan ke organ melalui neuron yang distimulasi melalui titik refleks di tangan dan kaki (Ernst, Posadzki,Lee, 2010). ${ }^{6}$

Penelitian yang dilakukan oleh Aydin, Aslan, Yalcin, 2016, ${ }^{5}$ pada wanita dengan $\mathrm{OAB}$ (Overactive Bladder Symptom) yang memiliki gejala depresi, ditemukan bahwa gejala depresi ringan dan tingkat sedang ditemukan menurun secara berarti setelah 
dilakukannya pijat refleksi, dan gejala depresi berat ditemukan tidak ada setelah dilakukannya pijat refleksi.

Alat skrining depresi yang paling umum digunakan untuk orang dewasa adalah Geriatric Depression Scales (GDS) 15 dan GDS 30. Secara lokal, studi validasi oleh Ramlall et al., pada tahun $2013^{7}$ mendukung penggunaan kedua versi GDS tersebut tanpa adanya pengaruh yang signifikan terhadap kinerja dari GDS tersebut karena ras, usia, jenis kelamin atau tingkat pendidikan.

Provinsi Jawa Barat merupakan salah satu provinsi yang masuk kedalam 10 besar jumlah lansia terbanyak tahun 2015 dengan presentase jumlah lansia sebesar $8,5 \%$ (Pusat Data Dan Informasi, 2016). ${ }^{8}$

\section{Metode}

Penelitian ini menggunakan design quasi experimental design dengan rancangan pre dan post pada kelompok lansia $\geq 60$ tahun. Pada penelitian ini lansa dilakukan wawancara dengan GDS sebelum mendapat perlakuan. Langkah berikutnya adalah diberikan perlakuan pijat refleksi pada kaki secara bergantian untuk mengurangi depresi. Setelah selesai intervensi kemudian dilakukan wawancara GDS yang kedua. Hasil selisih skor rata-rata GDS dibandingkan untuk melihat sejauh mana pengaruh intervensi pijat refleksi terhadap penurunan depresi pada lansia

Variabel penelitian dalam penelitian ini meliputi usia, status pernikahan, pendidikan, pijat refleksi dan depresi. Pengumpulan data ini dilakukan pada lansia yang berusia $\geq 60$ tahun di balai desa. Perlakuan dilakukan pada lansia yang memenuhi kriteria inklusi dan eksklusi. Setiap lansia akan diberikan intervensi pijat refleksi setiap 2x seminggu dengan durasi 100-140 menit.

Populasi dari penelitian adalah lansia $\geq 60$ tahun di Desa Puraseda, Kecamatan Leuwiliang, Kabupaten Bogor Jawa Barat. Cara pengambilan sampel menggunakan teknik random sampling yang memenuhi kriteria inklusi sampai memenuhi jumlah responden yang diinginkan, dimana jumlah sampel yang ditargetkan didapatkan dengan rumus dibawah ini Sumber: Ariawan, $1998^{25}$

$$
S p^{2}=\frac{\left[\left(n_{1}-1\right) S_{1}{ }^{2}+\left(n^{2}-1\right) S_{2}{ }^{2}\right]}{\left(n_{1}-1\right)+\left(n_{2}-1\right)} \quad n=\frac{2 \sigma^{2}\left[z_{1-\alpha}^{2}+z_{1-\beta}\right]^{2}}{\left(\mu_{1}-\mu_{2}\right)^{2}}
$$

\section{Keterangan :}

- $\mathrm{Z} 1-\alpha / 2=$ Derajat kemaknaan sebesar 5\%

- $Z 1-\beta=$ Derajat kekuatan uji sebesar $80 \%$

- $\mu 1=$ rata-rata skor setelah intervensi (Jurnal $1=$ Shahidi, M., et al, 2010). ${ }^{26}$

- $\mu 2=$ rata-rata skor setelah intervensi (Jurnal $2=$ Kim, S.H., et al, 2011). ${ }^{27}$ 


$$
\begin{aligned}
& \qquad \text { sp }^{2} \text { atau } \sigma^{2}=\frac{\left[(20-1) 6,9^{2}+(26-1) 3,05^{2}\right]}{(20-1)+(26-1)} \\
& =\frac{\left[(19) 6,9^{2}+(25) 3,05^{2}\right]}{(19)+(25)} \\
& =\frac{[904,59+232,5625]}{44} \\
& =\frac{[1137,152]}{44} \\
& =25,84436
\end{aligned}
$$

Lalu dapat dicari nilai n nya seperti:

$$
\begin{gathered}
n=\frac{2.25,84436\{1,96+0,84\}^{2}}{(10-3,39)^{2}} \\
n=\frac{405,2396}{43,6921} \\
n=9,27 \quad \text { *dibulatkan menjadi } 10
\end{gathered}
$$

Sampel yang terlibat dalam penelitian ini berdasarka hasil perhitungan sebanyak 10 , akan tetapi peneliti mentargetkan sampel sebanyak 20 responden.

\section{Kriteria inklusi}

1. Lansia berusia diatas 60 tahun.

2. Tinggal di Desa Puraseda paling sedikit 3 tahun.

\section{Kriteria ekslusi}

1. Lansia yang tidak komunikatif.

2. Lansia yang tidak mampu mobilisasi secara mandiri.

3. Lansia yang mempunyai penyakit jantung yang didiagnosa oleh dokter

\section{Kriteria drop out}

Subjek di drop out jika tidak mengikuti latihan sebanyak $3 x$ selama intervensi.

Pengolahan data dilakukan dalam beberapa tahap, yaitu : editing, koding, dan entry data. Proses editing dilakukan untuk memeriksa kelengkapan data yang dikumpulkan, kemudian dilakukan koding dengan pemberian kode oleh peneliti untuk variabel yang telah dikumpulkan sesuai dengan kriterianya masing-masing. Selanjutnya datadata tersebut dimasukkan (entry) kedalam komputer untuk dilakukan proses analisis. Analisis yang digunakan adalah meliputi analisis univariat, bivariat dan multivariat.

\section{Hasil}

A. Analisis Univariat 


\section{Tabel 5.1}

\section{Distribusi Frekuensi Karakteristik Responden}

\begin{tabular}{|c|c|c|c|c|}
\hline Karakteristik Subjek & Rata-Rata \pm SD & Min & Max & CI 95\% \\
\hline Usia & $65,40 \pm 5,34$ & 60 & 72 & $62,90-67,90$ \\
\hline Laki-laki & $64,88 \pm 5,64$ & 60 & 72 & $60,16-69,59$ \\
\hline Perempuan & $65,75 \pm 5.36$ & 60 & 72 & $62.34-69.16$ \\
\hline \multicolumn{5}{|l|}{ Skor Depresi } \\
\hline Sebelum Intervensi & $18,60 \pm 3,01$ & 12 & 23 & $17,19-20,01$ \\
\hline Sesudah Intervensi & $16,20 \pm 2,68$ & 12 & 21 & $14,94-17,96$ \\
\hline \multicolumn{5}{|l|}{ Disforik } \\
\hline Sebelum Intervensi & $3,65 \pm 1,89$ & 0,00 & 6,00 & $2,76-4,54$ \\
\hline Sesudah Intervensi & $2,25 \pm 1,29$ & 0,00 & 5,00 & $1,64-2,85$ \\
\hline \multicolumn{5}{|l|}{ Mood } \\
\hline Sebelum Intervensi & $5,30 \pm 0,98$ & 3,00 & 6,00 & $4,84-5,76$ \\
\hline Sesudah Intervensi & $5,60 \pm 0,75$ & 3,00 & 6,00 & $5,25-5,95$ \\
\hline \multicolumn{5}{|l|}{ Apatis } \\
\hline Sebelum Intervensi & $1,55 \pm 1,09$ & 0,00 & 4,00 & $1,04-2,06$ \\
\hline Sesudah Intervensi & $1,15 \pm 0,99$ & 0,00 & 3,00 & $0,69-1,61$ \\
\hline \multicolumn{5}{|l|}{ Keputusasaan } \\
\hline Sebelum Intervensi & $2,26 \pm 0,64$ & 1,00 & 3,00 & $1,95-2,55$ \\
\hline Sesudah Intervensi & $2,25 \pm 0,64$ & 1,00 & 3,00 & $1,95-2,55$ \\
\hline \multicolumn{5}{|l|}{ Penarikan Diri } \\
\hline Sebelum Intervensi & $2,40 \pm 0,99$ & 1,00 & 4,00 & $1,94-2.87$ \\
\hline Sesudah Intervensi & $1,50 \pm 1,00$ & 0,00 & 3,00 & $1,03-1,97$ \\
\hline \multicolumn{5}{|l|}{ Penurunan Konsentrasi } \\
\hline Sebelum Intervensi & $1,60 \pm 0,59$ & 0,00 & 2,00 & $1,32-1,88$ \\
\hline Sesudah Intervensi & $1,50 \pm 0,61$ & 0,00 & 2,00 & $1,22-1,78$ \\
\hline \multicolumn{5}{|l|}{ Kelemahan Kognitif } \\
\hline Sebelum Intervensi & $1,85 \pm 0,82$ & 1,00 & 3,00 & $1,47-2,23$ \\
\hline Sesudah Intervensi & $1,70 \pm 0,66$ & 1,00 & 3,00 & $1,39-2,01$ \\
\hline
\end{tabular}

Dari data

karakteristik subjek penelitian diatas, dapat dilihat bahwa terdapat range usia rata-rata \pm SD keseluruhan yaitu $65,40 \pm 5,345$ dengan usia minimal 60 tahun dan maksimal 72 tahun dengan CI 95\% (61,90 -67,90). Dimana usia rata-rata \pm SD laki-laki adalah 64,88 \pm 5,643 rata-rata usia perempuan adalah $65,75 \pm 5,362$.
Rata-rata keseluruhan skor komponen GDS mengalami penurunan setelah diberikannya pijat refleksi sehingga adanya pengaruh pijat refleksi pada lansia dimana ratarata skor depresi sebelum dilakukannya pijat refleksi adalah 18,60 dengan standar deviasi 3,01. Rata-rata skor depresi sesudah 
intervensi pijat refleksi adalah 16,20

dengan standar deviasi 2,68.

Tabel 5.2

Distribusi Karakteristik Subjek Berdasarkan Jenis Kelamin

\begin{tabular}{ccc}
\hline Jenis Kelamin & N & Persentase \\
\hline Laki-laki & 8 & $\mathbf{4 0 \%}$ \\
Perempuan & 12 & $\mathbf{6 0 \%}$ \\
\hline
\end{tabular}

Dari data diatas dapat dilihat bahwa sampel dengan jenis kelamin lebih banyak dibanding dengan jenis kelamin laki-laki (60\%).

\section{B. Analisis Bivariat}

Sebelum melakukan analisis manfaat

intervensi dengan analisis bivariat dilakukan terlebih dahulu uji normalitas skor depresi sebelum dan sesudah intervensi.

\section{Tabel 5.3}

Normalitas Rerata Sebelum Dan Sesudah Intervensi Subjek Penelitian $(\mathbf{n}=\mathbf{2 0})$

\begin{tabular}{ccc}
\hline Skor Depresi & Hasil Uji Normalitas & Keterangan \\
\hline Sebelum Intervensi & 0,58 & Distribusi normal \\
Sesudah Intervensi & 0,37 & Distribusi normal \\
\hline
\end{tabular}

Pada tabel diatas nilai signifikan sebelum intervensi 0,58, >0,05 yang berarti data sebelum intervensi diatas berdistribusi normal dan sesudah intervensi 0,37, >0,05 yang berarti distribusi normal. Karna dalam uji normalitas skor depresi didapatkan hasil normal dan normal maka digunakan uji $t$ paired test.
Pada tabel diatas nilai signifikan sebelum intervensi 0,200, >0,05 yang berarti data sebelum intervensi diatas berdistribusi normal dan sesudah intervensi 0,200, <0,05 yang berarti distribusi normal. Karna dalam uji normalitas skor depresi didapatkan hasil normal dan normal maka digunakan uji $t$ paired test. 
Hasil Uji T-Paired Test

\begin{tabular}{cccc}
\hline Skor Depresi & Mean \pm SD & CI (95\%) & P \\
\hline Sebelum - sesudah & $2.40 \pm 3,45$ & $0,78-4,01$ & $\mathbf{0 , 0 0 6}$ \\
\hline
\end{tabular}

*Paired T-Test dengan nilai p bermakna

Hasil Uji Paired t-test, diperoleh signifikasi $0,006(\mathrm{p}<0,05)$ dengan selisih rata-rata sebelum dan sesudah sebesar $2.40 \pm 3,45$. Karena nilai $\mathrm{p}<0,05$ sehingga $\mathrm{H}_{0}$ ditolak dan
$\mathrm{H}_{1}$ diterima yang menandakan adanya pengaruh skor depresi sebelum dan sesudah intevensi.

Tabel 5.5

Distribusi Frekuensi Sebelum Dan Sesudah Dilakukannya Intervensi Pijat refleksi

\begin{tabular}{ccccccc}
\hline \multicolumn{7}{c}{ Depresi } \\
\hline & \multicolumn{1}{c}{ Tidak Depresi } & \multicolumn{2}{c}{ Depresi ringan } & \multicolumn{2}{c}{ Depresi berat } \\
& $\mathrm{N}$ & $\%$ & $\mathrm{~N}$ & $\%$ & $\mathrm{~N}$ & $\%$ \\
Sebelum & 0 & $0 \%$ & 13 & 65 & 7 & 35 \\
Sesudah & 0 & $0 \%$ & 17 & 85 & 3 & 15 \\
\hline
\end{tabular}

Depresi dapat dikategorikan menjadi tidak depresi, depresi ringan, dan depresi berat. Pengkategorian ini menurut Yesavage et al., adalah, 0-9 adalah tidak depresi, 10-19 depresi ringan, 20-30 depresi berat.

Dari tabel diatas dapat dilihat bahwa setelah subjek yang mengalami depresi ringan dan berat sebelum dilakukannya pijat refleksi sebanyak 13 orang $(65 \%)$ dan 7 orang (35\%). Setelah dilakukannya pijat refleksi subjek yang depresi ringan dan berat sebanyak 27 orang (85\%) dan 3 orang (15\%).

\section{PEMBAHASAN}

Hasil penelitian ini didapatkan rata-rata usia lansia (Tabel 5.1) sebesar 65,40 $\pm 5,345$ tahun dan menurut jenis kelamin (Tabel 5.2) lebih banyak perempuan sebanyak 12 subjek atau dengan persentase sebanyak (60\%). Hal ini kemungkinan dikarenakan usia angka harapan hidup lebih besar perempuan daripada laki-laki menurut perkiraan Central Intelegence Agency World Factbook (2011). Angka harapan hidup dunia tercatat sebesar 66,57 tahun (untuk laki-laki 64,52 tahun dan untuk perempuan 68,76) pada tahun 2009. Sedangkan pada Indonesia, angka harapan hidup tercatat sebesar 70,76 tahun (pada lakilaki sebesar 60,26 tahun dan padaperempuan sebesar 73,38 tahun).

Berdasarkan frekuensi data subjek penelitian didapatkan sebelum intervensi subjek yang memiliki skor depresi ringan adalah sebanyak 13 subjek (65\%) dan skor depresi parah sebanyak 7 subjek (35\%). Sedangkan sesudah intervensi subjek yang memiliki skor depresi ringan sebanyak 17 subjek (85\%) dan skor depresi parah sebanyak 3 subjek (15\%) (Tabel 5.2). Ini menandakan bahwa adanya pengaruh skor depresi pada lansia. 
Dari hasil analisis intervensi pijat refleksi sebelum dan sesudah terhadap skor depresi lansia selama 5 minggu menyatakan adanya pengaruh intervensi pijat refleksi. Rata-rata skor depresi berdasarkan Geriatric Depression Scale (GDS) (Tabel 5.1) didapatkan skor depresi sebelum intervensi adalah 18,60 $\pm 3,01$ (CI 95\% 17,19-20,01) dan rata-rata skor depresi setelah intervensi

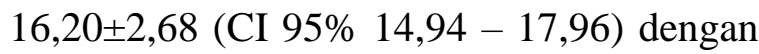
nilai $\mathrm{p}=0,006$ artiya $\mathrm{p} \quad<0,05$ yang menyatakan bahwa $\mathrm{H}_{0}$ ditolak dan $\mathrm{H}_{1}$ diterima yang menandakan adanya pengaruh skor depresi sebelum dan sesudah intevensi. Hal ini sejalan dengan penelitian yang dilakukan oleh Aydin, Aslan, Yalcin 2016 pada wanita dengan $\mathrm{OAB}($ Overactive Bladder Symptom) yang memiliki gejala depresi, ditemukan bahwa gejala depresi ringan dan depresi tingkat sedang ditemukan menurun secara berarti setelah dilakukannya pijat refleksi, dan gejala depresi berat ditemukan tidak ada setelah dilakukannya pijat refleksi.

Menurut Wang et al., 2008 pijat refleksi didefinisikan sebagai aplikasi tekanan yang sistematis terhadap titik refleks spesifik pada kaki dengan tujuan untuk menunjukkan pengaruh homeostasis, relaksasi,dan respon healing. Penelitian yang dilakukan oleh McCullough, Liddle, Sinclair, \& Hughes., 2014. "Teori impuls saraf" mengatakan bahwa stimulasi yang diterapkan pada titik pijat refleksi spesifik di kaki bisa meningkatkan koneksi saraf ke bagian tubuh yang sesuai. Hal ini merupakan teori yang paling menjanjikan dan menunjukkan bahwa manfaat pijat refleksi dapat dilakukan dengan modulasi sistem saraf otonom (ANS).
Penelitian yang dilakukan oleh Krohn, et al., 2011 yang meneliti pengaruh pijat terhadap depresi dengan pemberian terapi pijat yang dilakukan sebanyak dua kali seminggu selama 5 minggu dengan durasi 30 menit setiap pertemuan hasilnya adalah setelah dilakukannya terapi pijat score depresi (PHQ) berkurang secara signifikan, dan skor depresi cemas (BSF) juga berkurang. Beberapa factor yang mempengaruhi depresi secara signifikan adalah usia, jenis kelamin, aktifitas fisik, status merokok, mood, stress, kecemasan.

Ada beberapa factor yang menyebabkan penurunan skor depresi tidak signifikan, diantaranya adalah teknik refleksi yang dilakukan kurang maksimal. Karena jam terbang maupun pengalaman terapis masih kurang, jumlah subjek kurang banyak dan kuisioner GDS yang bersifat subjektif.

\section{Saran}

Disarankan untuk menghindari hal-hal yang membuat banyak pikiran yang akan menimbulkan stress, kecemasan yang akan mengakibatkan perubahan peningkatan skor depresi pada lansia. Hasil penelitian ini diharapkan dapat meningkatkan pengetahuan masyarakat khususnya keluarga yang memiliki lansia untuk lebih memperhatikan lansia sehingga menghambat meningkatnya skor depresi pada lansia. Juga untuk pihak keluarga diharapkan bisa menerapkan intervensi pijat refleksi secara berkala, baik dilakukan sendiri atau berkunjung ke tempat refleksi yang secara resmi. 


\section{DAFTAR PUSTAKA}

1. World Health Organization (WHO). “ Definition of an older or elderly person ". 29 April 2019. (http://www.who.int/healthinfo/survey/ag eingdefnolder/en/).

2. Bjørkløf,G.H., Engedal, K., Selbæk G., Kouwenhoven, S.K., Helvik A.S. (2013). Coping and Depression in Old Age:A Literature Review. Dement Geriatr Cogn Disord. 35:121- 154.

3. World Health Organization, 2013. Mental Health and Older Adults. Di ambil dari http://www.who.int/mediacentre/factshe ets/ fs381/en/index.html.

4. Nilsson, K., Gustafson, L., Hultberg, B. (2011). Survival in a Large Elderly Population of Patients with Dementia and Other Forms of Psychogeriatric Diseases. Dement Geriatr Cogn Disord. 32:342350.

5. Aydin, Y., Aslan, E., Yalcin, O. (2016). Effect of Reflexology to Depressive Symptoms in Women With Overactive Bladder. Holist Nurs Pract. 30(5):294 300.

6. Ernst, P., Posadzki, P., Lee,M.S. Reflexology: An update of a systematic review of randomised clinical trials. Maturitas. 116-120.

7. Ramlall, S. Screening for and diagnosing dementia in an elderly residential home population: a validation study; 2013, Unpublished data.

8. Infodatin Pusat Data Dan Informasi Kementrian Republik Indonesia. (2016). Situasi Lanjut

Usia

Lansia)

$i$

ndonesia.

(http://www.pusdatin.kemkes.go.id/folde r/view/01/structure-publikasi-pusdatininfo- datin.html).

9. De Freitas, M. C., Queiroz, T. A., \& De Sousa, J. A. V. (2010). The meaning of old age and the aging experience of in the elderly. Revista Da Escola De Enfermagem Da USP; 44(2), 407-412. https://doi.org/10.1590/S0080$\underline{62342010000200024}$.

10. Zizza, C. A., Ellison, K. J., \& Wernette, C. M. (2009). Total Water Intakes of Community Living Middle-Old and Oldest-Old Adults. J Gerontol A Biol Sci Med Sci, 64(4), 481-486. https://doi.org/10.1093/gerona/gln045

11. Depkes. " Lansia Yang Sehat, Lansia Yang Jauh Dari Demensia “. 29 April 2016.

(http://www.depkes.go.id/article/print/16 031000003/menkes-lansia-yang-sehatlansia-yang-jauh-dari-demensia.html). 
12. InfoDATin Kemenkes.(2014).Situasi dan Analisis Lanjut Usia. http://www.pusdatin.kemkes.go.id/folder /view/01/structure-publikasi-pusdatininfo- datin.html.

13. Kaplan, H.I., Sadock, B.J., and Grebb, J.A., (2010). Sinopsis Psikiatri : Ilmu Pengetahuan Perilaku Psikiatri Klinis. Jilid Dua. Editor : Dr. I. Made Wiguna S. Jakarta : Bina Rupa Aksara.

14. Solhaug, H.I., Romuld. E.B., Romild, U, Stordal, E. (2012) Increased prevalence of depression in cohorts of the elderly: an 11-year follow-up in the general population-the HUNT study. Int Psychogeriatr.24:151-15.

15. Thielke, S.M., Diehr, P., Unutzer, J. (2010) Prevalence, incidence, and persistence of major depressive symptoms in the Cardiovascular health study. Aging Ment Health. 14:168-176.

16. Rajkumar, A.P., Thangadurai, P., Sentilkumar, P.,Gayathri, K., Prince, M., Jacob, K.S. (2009). Nature, prevalence and factors associated with depression among the elderly in a rural south Indian community. International Psychogeriatrics. 21:2, 372-378.

17. Huang, S.S., Liao, Y.C., Wang, W.F. (2016). The Factor Structure for the Geriatric Depression Scale in Screening Depression in Taiwanese Patients with Very Mild to Moderate Dementia. International Journal of Gerontology.http://dx.doi.org/10.1016/j.i jge.2016.03.011
18. Hendro G.S., (2014). Ilmu Pijat Pengobatan Refleksi.

19. Altun, F.; Yazici, H. The relationships between life satisfaction, gender, social security, and depressive symptoms among elderly in Turkey. Educ. Gerontol. 2015, 41, 305-314.

20. Avila, R., Moscoso,M.A.,Ribeiz,S., Arrais,J.,Jaluul, O.,Bottino, C.M. (2009). Influence of education and depressive symptoms on cognitive function in the elderly. Int Psychogeriatr. 21(3):560-7. doi: $10.1017 /$ S1041610209008928.

21. Weinberger, A.H., Kashan,R.S., Shpigel, D.M., Esan, H., Taha, F., Lee, C.J., Funk, A.P., Goodwin, R.D. (2016). Depression and cigarette smoking behavior: a critical review of population-based studies. The American Journal Of Drug And Alcohol Abuse.

22. Bishwajit G, O'Leary DP, Ghosh S, Yaya S, Shangfeng T, Feng Z. (2017). Physical inactivity and self-reported depression among middle-and older-aged population in South Asia: world health survey.BMC Geriatr. 17:100.

23. Krohn, M., Listing, M., Tjahjono, G., Reisshauer, A., Peters, E., Klapp, B.F., Rauchfuss, M. (2010). Depression, mood, stress, and Th1/Th2 immune balance in primary breast cancer patients undergoing classical massage therapy. Support Care Cancer 19:1303- 1311. DOI 10.1007/s00520-010-0946-2.

24. Krogh, J., Nordentoft, M., Sterne, J.A., Lawlor, D.A. (2011). The effect of exercise in clinically depressed adults: 
systematic review and meta-analysis of randomized controlled trials. J Clin Psychiatry. 7

25. Ariawan, I. (1998). Besar Dan Metode Sampel Dalam Penelitian Kesehatan. Universitas Indonesia.
26. Shahidi, M., Mojtahed, A., Modabbernia, A., Mojtahed, M., Shafiabady, A., Delavar, A., Honari, H. (2010). Laughter Yoga versus group exercise program in elderly depressed women: a randomized controlled trial. Int J Geriatr Psychiatry. DOI:10.1002/gps.2545.

27. Kim, S.H., Kim, M., Ahn, Y.B., Lim, H.K., Kang, S.G., Cho, J.H., Park, S.J., Song, S.W. (2011). Effect of dance exercise on cognitive function in elderly patients with metabolic syndrome: A pilot study. Journal of Sports Science and Medicine. 10. 671-678 